\title{
A Coarse-Graining Approach for the Proton Complex in Protonated Aluminosilicates
}

\author{
S. Calero, ${ }^{*}, \uparrow$ M. D. Lobato,${ }^{\dagger}$ E. García-Pérez,${ }^{\dagger}$ J. A. Mejías,${ }^{\dagger}$ S. Lago ${ }^{\dagger}{ }^{\dagger}$ T. J. H. Vlugt,, \\ T. L. M. Maesen,,$^{\S}$ B. Smit, ${ }^{\prime \prime \perp}$ and D. Dubbeldam" \\ Department of Environmental Sciences, University Pablo de Olavide, Ctra. Utrera km 1. 41013 Sevilla, Spain, \\ Condensed Matter and Interfaces, Debye Institute, Utrecht University, P.O.Box 80.000, 3508 TA Utrecht, \\ The Netherlands, Energy Research and Technology Center, Chevron Texaco, Chevron Way 100, \\ Richmond California 94802-0627, Van't Hoff Institute for Molecular Sciences, University of Amsterdam, \\ Nieuwe Achtergracht 166, 1018 WV Amsterdam, The Netherlands, and Centre Européen de Calcul Atomique et \\ Moléculaire (CECAM), Ecole Normale Supérieure, 46 Allée d'Italie, 69007 Lyon, France
}

Received: January 10, 2006; In Final Form: February 14, 2006

\begin{abstract}
We have developed a computational framework for the adsorption of linear alkanes in protonated aluminosilicates. These zeolites contain trace amounts of water that form hydrated proton complexes. The presence of hydrated protons makes the simulations at the fully atomistic level difficult. Instead of constructing an elaborate and complex model, we show that an approach based on a coarse-graining of the proton-complex accurately describes the available experimental isotherms, Henry coefficients, heats of adsorption, and oxygenproton distances. Our approach is supported by MP2 quantum mechanical simulations. The model gives remarkably good agreement with experimental data beyond the initial calibration set.
\end{abstract}

Zeolites are aluminosilicates with pore sizes comparable to the molecular size. They offer outstanding potential for molecular recognition at the subnanometer level and the ability to operate at high temperatures. ${ }^{1,2}$ Computer simulations of allsilica structures have been steadily advancing over the past decade, and the current state-of-the-art models show very good agreement with adsorption data from experiments. ${ }^{3}$ It has been widely believed that for complex systems, such as protonated aluminosilicates, much more sophisticated potential forms are needed. One would like to construct a model able to accurately reproduce results within the range of experiments but that would also predict results with confidence in the range of costly and difficult experimental conditions. The true test of a coarsegraining approach is the performance beyond the calibration set.

Protonated aluminosilicates are extremely hygroscopic and readily adsorb traces of water. ${ }^{4,5}$ Several authors have reported linear relationships between the amount of aluminum per unit cell of the zeolite and the amount of water adsorbed (see ref 6 and references therein). Although the precise amount of water is often not reported or measured, it is most likely that water molecules are in close proximity to the protons and provide a shielded environment. Simulating the interaction between that hydrated proton complex, $\mathrm{H}_{2 n+1} \mathrm{O}_{n}{ }^{+}$, and the alkanes by means of a fully atomistic model is challenging for several reasons. First, thermal movement will cause charge fluctuations within the $\mathrm{H}_{2 n+1} \mathrm{O}_{n}{ }^{+}$complex, this will lead to fluctuating polarization

\footnotetext{
* Corresponding author. E-mail: scaldia@upo.es

† University Pablo de Olavide.

$\doteqdot$ Utrecht University.

$\S$ Chevron Texaco.

"University of Amsterdam.

$\perp$ Ecole Normale Supérieure.
}

interactions between the complex and its environment that are difficult to describe in a simulation. Second, it is most likely that the proton behaves as a quantum particle within these hydrated complexes. Finally, there is uncertainty about the number of water molecules hydrating the proton. To circumvent these difficulties we have chosen to coarse-grain the proton complex as a single interaction center. The term coarse-grain is used to emphasize the difference with a conventional unitedatom approach where a group of covalently bonded atoms is united into a single interaction center, while here the proton complex consists of molecules of different type and amount. In this model all the proton-water interactions and all the charge fluctuations are averaged. The model is fitted to experimental data on the adsorption of linear alkanes in aluminosilicates containing protons and retains the accuracy and simplicity of the united-atom approach. We show in this letter that such a coarse-graining approach using effective potentials gives surprisingly good agreement with experiments. Since this approach is much in the same spirit as the united atom models, it is therefore easy to combine with preexisting models.

Our coarse-grained model is described in Table 1. We use the united-atom $\operatorname{model}^{7}$ for the alkanes and consider the $\mathrm{CH}_{x}$ groups as single interaction centers with their own effective potentials. The beads in the chain are connected by harmonic bonding potentials. A harmonic cosine bending potential models the bond bending between three neighboring beads, a RyckaertBellemans potential controls the torsional angle. The beads in a chain separated by more than three bonds interact with each other through a Lennard-Jones potential. The interactions between the rigid framework and the guest molecules are assumed to be dominated by the oxygen atoms. ${ }^{8}$ Note that the framework is kept rigid, but the proton complexes are allowed to move. Interactions between the complexes are dominated by 
TABLE 1: Lennard-Jones Force Field Parameters ${ }^{a}$

\begin{tabular}{llllll}
\hline & & $\mathrm{CH}_{4}$ & $\mathrm{CH}_{3}$ & $\mathrm{CH}_{2}$ & $\mathrm{H}_{2 n+1} \mathrm{O}^{+}{ }_{n}$ \\
\hline $\mathrm{O}_{\mathrm{Si}}$ & $\epsilon / k_{\mathrm{B}}[\mathrm{K}]$ & 115 & 93.0 & 60.5 & 20.0 \\
& $\sigma[\AA]$ & 3.47 & 3.48 & 3.58 & 1.41 \\
$\mathrm{O}_{\mathrm{Al}}$ & $\epsilon / k_{\mathrm{B}}[\mathrm{K}]$ & 115 & 93.0 & 60.5 & 20.0 \\
& $\sigma[\AA]$ & 3.47 & 3.48 & 3.58 & 1.41 \\
$\mathrm{H}_{2 n+1} \mathrm{O}^{+}{ }_{n}$ & $\epsilon / k_{\mathrm{B}}[\mathrm{K}]$ & 260 & 215 & 300.0 & - \\
& $\sigma[\AA]$ & 4.6 & 4.7 & 5.0 & - \\
$\mathrm{CH}_{4}$ & $\epsilon / k_{\mathrm{B}}[\mathrm{K}]$ & 158.5 & 130.84 & 94.21 & 260.0 \\
& $\sigma[\AA]$ & 3.72 & 3.74 & 3.84 & 4.6 \\
$\mathrm{CH}_{3}$ & $\epsilon / k_{\mathrm{B}}[\mathrm{K}]$ & 130.84 & 108.0 & 77.7 & 215.0 \\
& $\sigma[\AA]$ & 3.74 & 3.76 & 3.86 & 4.7 \\
$\mathrm{CH}_{2}$ & $\epsilon / k_{\mathrm{B}}[\mathrm{K}]$ & 94.21 & 77.7 & 56.0 & 300.0 \\
& $\sigma[\AA]$ & 3.84 & 3.86 & 3.96 & 5.0 \\
$\mathrm{LJ}$ & \multicolumn{5}{c}{$U_{i j}=4 \epsilon_{i j}\left[\left(\sigma_{i j} / r_{i j}\right)^{12}-\left(\sigma_{i j} / r_{i j}\right)^{6}\right]$} \\
charge & $\mathrm{O}_{\mathrm{Si}}$ & $\mathrm{O}_{\mathrm{Al}} \quad \mathrm{H}_{2 n+1} \mathrm{O}^{+}{ }_{n} \quad \mathrm{Si}$ & $\mathrm{Al}$ \\
& -0.8 & -0.9 & +0.8 & +1.6 & +1.2 \\
bond & \multicolumn{5}{c}{$U^{\text {bond }}=1 / 2 k_{1}\left(r-r_{0}\right)^{2}$} \\
bend & \multicolumn{5}{c}{$k_{2} / k_{\mathrm{B}}=96500 \mathrm{~K} / \AA^{2}, r_{0}=1.54 \AA$} \\
torsion & \multicolumn{5}{c}{$k_{2} / k_{\mathrm{B}}=62500 \mathrm{~K}, \theta_{0}=114^{\circ}$} \\
& \multicolumn{5}{c}{$U^{\text {torsion }}=\sum_{n=0}^{5} \eta n \cos ^{n} \phi$} \\
& \multicolumn{5}{c}{$-1944.666,715.690,-1565.572\}$}
\end{tabular}

${ }^{a} \mathrm{O}_{\mathrm{Al}}$ are oxygens bridging one silicon and one aluminum atom, and $\mathrm{O}_{\mathrm{Si}}$ are oxygens bridging two silicon atoms. The charge in atomic units, the bond and bend parameters, the torsion potential, and the $\mathrm{O}-\mathrm{CH}_{x}$ interactions are taken from our previous works. ${ }^{3,10}$ Note that although the zeolite framework itself is kept rigid, the proton complex is allowed to move.

TABLE 2: Average Occupancies and $\mathrm{H}^{+}-\mathrm{O}$ Distances for FAU-type Zeolites Obtained by Monte Carlo Simulations Occupancies

\begin{tabular}{|c|c|c|c|c|c|}
\hline & $\mathrm{O}_{1}$ & $\mathrm{O}_{2}$ & $\mathrm{O}_{3}$ & $\mathrm{O}_{4}$ & total O \\
\hline this work $58 \mathrm{H}^{+}$ & 22.1 & 10.6 & 19.7 & 5.6 & 58 \\
\hline ref 18 & 28.6 & 9.5 & 15 & 0 & 53.1 \\
\hline ref 19 & 21.2 & 0 & 30.9 & 0.1 & 52.2 \\
\hline ref 20 & 18 & 0 & 16 & 0 & 34 \\
\hline ref 21 & 27 & 0 & 32 & 0 & 59 \\
\hline \multicolumn{6}{|c|}{ Distances } \\
\hline & $\mathrm{H}^{+}-\mathrm{O}_{1}$ & $\mathrm{H}^{+}-\mathrm{O}_{2}$ & \multicolumn{2}{|c|}{$\mathrm{H}^{+}-\mathrm{O}_{3}$} & $\mathrm{H}^{+}-\mathrm{O}_{4}$ \\
\hline this work $58 \mathrm{H}^{+}$ & 0.958 & 1.011 & \multicolumn{2}{|c|}{0.991} & 1.156 \\
\hline ref 18 & 0.83 & 1.02 & \multicolumn{2}{|c|}{0.98} & - \\
\hline ref 22 & 0.97 & - & \multirow{2}{*}{\multicolumn{2}{|c|}{$\begin{array}{l}0.97 \\
1.18\end{array}$}} & - \\
\hline ref 23 & 1.17 & 1.16 & & & 1.16 \\
\hline
\end{tabular}

Coulombic interactions, and therefore the van der Waals interactions can be neglected. Some of the alkane-alkane interactions are taken from ref 9 and the $\mathrm{O}-\mathrm{CH}_{x}$ interactions are taken from our previous works. ${ }^{3,10}$ The positions of the aluminum in aluminosilicates are generally thought to be random, although for some zeolites preferential sites exist. Zeolite structures with fixed aluminum densities were obtained by randomly substituting silicon by aluminum, ${ }^{11}$ satisfying the Löwenstein rule. This affords a reasonable approximation of the framework aluminum distributions obtained by experimental methods. ${ }^{12}$ In Table 2 the oxygen-proton distances and occupancies are shown to be in good agreement with various experimental studies.

The coarse-grained potential parameters are obtained from fitting to full isotherms (cf. Figure 2a). Fitting to full isotherms uniquely determines the adsorbate-adsorbent interaction parameters, and it is very sensitive to the size parameters. ${ }^{10}$ Experimental data for protonated aluminosilicates is scarce. We use the set of Drago et al. ${ }^{13}$ to optimize the parameters for linear alkanes. The $\mathrm{H}_{2 n+1} \mathrm{O}_{n}{ }^{+}-\mathrm{CH}_{4},-\mathrm{CH}_{3}$, and $-\mathrm{CH}_{2} \mathrm{LJ}$ parameters

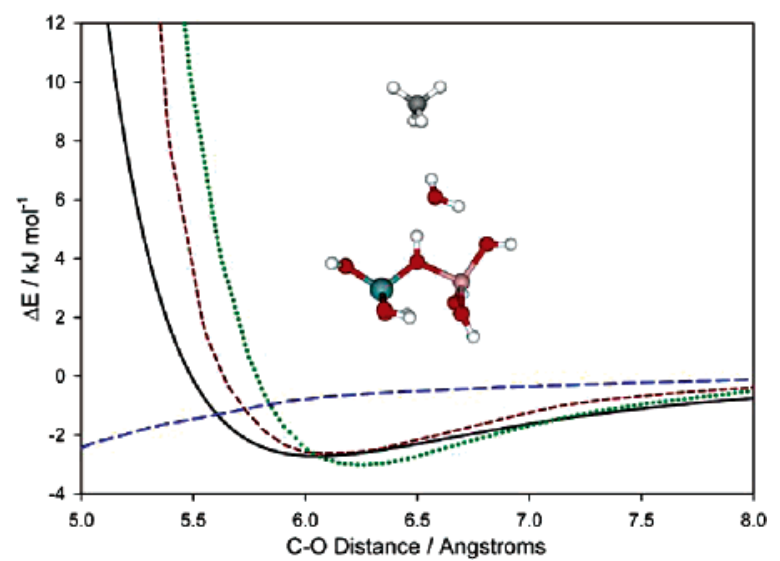

Figure 1. Interaction energies between $\mathrm{CH}_{4}$ and cluster models of proton in zeolites, as a function of distance between carbon and the $\mathrm{Si}-\mathrm{O}-\mathrm{Al}$ oxygen (the one that is bonded to the proton). Continuous black line: coarse-grained potential for $\mathrm{H}_{2 n+1} \mathrm{O}_{n}{ }^{+}-\mathrm{CH}_{4}$ and united atom potential for $\mathrm{O}-\mathrm{CH}_{4}$. Long blue dash: MP2 calculations of the interaction between $\mathrm{CH}_{4}$ and the proton zeolite site without water. Short brown dash: MP2 calculations of the interaction between $\mathrm{CH}_{4}$ and the proton zeolite site with one water molecule (structure shown in the inset). Green dots: MP2 calculations of the interaction between $\mathrm{CH}_{4}$ and the proton zeolite site with two water molecules. The curve for methane interacting with nonhydrated proton site has a minimum at about $3 \AA$ and around $-20 \mathrm{~kJ} / \mathrm{mol}$. This part of the curve is omitted for clarity to focus on the differences between the three other curves. The inset in the figure shows the structure of the complex formed by methane, one molecule of water, and the zeolite proton site.

are obtained from the methane, ethane, and propane isotherms, respectively. We stress that the parameters are unique, in the sense that only a single $(\epsilon, \sigma)$-LJ pair is able to describe the isotherm properly. The coarse-grained potential thus obtained yields an optimal $\mathrm{C}-\mathrm{O}$ distance of about $6.1 \AA$ and an interaction energy of about $-3 \mathrm{~kJ} / \mathrm{mol}$.

To asses in an independent manner that the coarse-grained $\mathrm{LJ}$ potential is representative of the interaction between the hydrated proton adsorbed on a zeolite and the hydrocarbon molecule, we have calculated the interaction energies between $\mathrm{CH}_{4}$ and cluster models of a proton in zeolites by means of our potential as well as by means of quantum mechanical MP2 calculations. In these calculations the methane molecule interacts with a protonated $\mathrm{O}_{3} \mathrm{Si}-\mathrm{OH}-\mathrm{AlO}_{3}$ unit. The terminal oxygens of this cluster are saturated with $\mathrm{H}$ in order to prevent dangling bonds. The geometries of the proton zeolite site, without water as well as with one and two water molecules H-bonded to the central proton, are fully optimized. The geometry of the $\mathrm{CH}_{4}$ moiety is fully optimized as well and then the total energy of the methane-zeolite cluster is calculated for several $\mathrm{C}-\mathrm{O}$ distances. The interaction energy is calculated by subtracting the energy of the proton zeolite model and the free $\mathrm{CH}_{4}$ molecule from the energy of $\mathrm{CH}_{4}$-water-zeolite complex. The basis set superposition error is corrected by using the counterpoise correction (see refs 14 and 15 and references therein). All calculations are done at the MP2 level with the $6-311+\mathrm{G}^{* *}$ basis set on all atoms and by using the Gaussian03 program. ${ }^{16}$

The comparison between the coarse-grained potential and the MP2 calculations that include different numbers of water molecules are presented in Figure 1. The differences between the MP2 calculations that include one or two water molecules on the proton and those without water are huge. The curve for methane interacting directly with the proton site, without water, has a minimum at about $3 \AA$ and the interaction energy is about $-20 \mathrm{~kJ} / \mathrm{mol}$. On the other hand, the interaction energy for methane interacting with hydrated proton sites has a minimum 
(a)

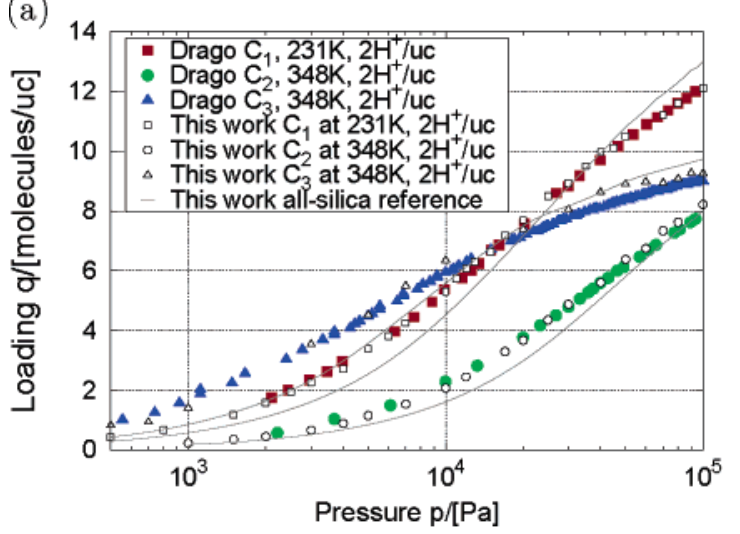

(c)

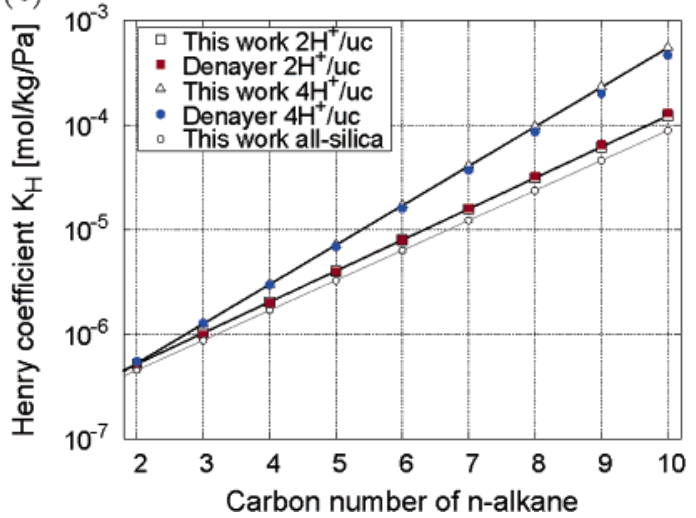

(b)

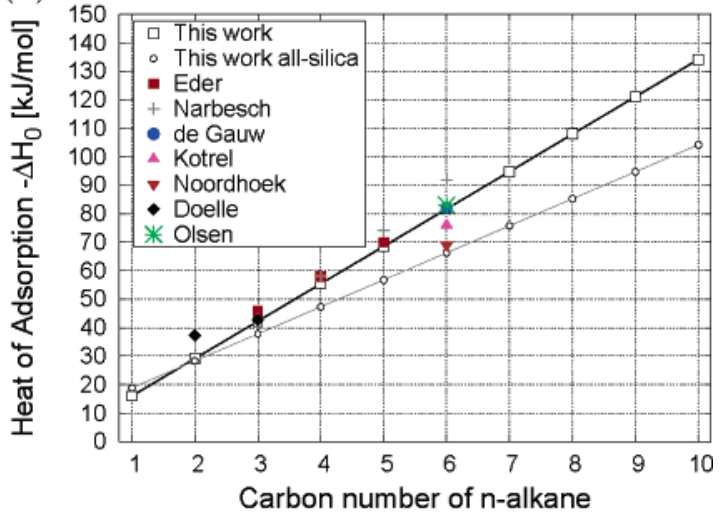

(d)

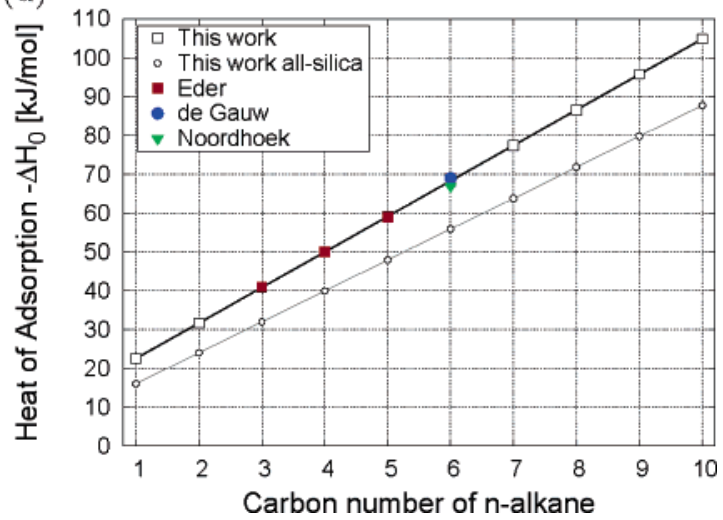

Figure 2. (a) Fitting to the experimentally measured isotherms of methane, ethane, and propane in the protonated MFI-type zeolite. ${ }^{13}$ (b) Prediction of the heat of adsorption for MFI-type zeolite with $3 \mathrm{H}^{+}$per unit cell. Comparison with available experimental data. ${ }^{24-29}$ (c) Prediction of the Henry coefficients at $573 \mathrm{~K}$ for a MFI-type protonated aluminosilicate with $2 \mathrm{H}^{+} / \mathrm{uc}$ and $4 \mathrm{H}^{+} / \mathrm{uc}$. Comparison with available experimental data. ${ }^{30}$ (d) Prediction of the heat of adsorption for MOR-type zeolite with $4 \mathrm{H}^{+}$per unit cell. Comparison with available experimental data. ${ }^{24,26,29}$

at around 6 or $6.5 \AA$, and the interaction energies are near -3 $\mathrm{kJ} / \mathrm{mol}$. This results show clearly that the presence of the proton-water complex leads to a larger $\mathrm{O}-\mathrm{CH}_{x}$ distance and a weaker attraction. In addition, from our QM calculations we conclude that the water basically screens the charge interaction with the nonpolar alkanes. These data as well as the shape of the interaction curve are in good agreement with the MP2 calculations that include one or two water molecules on the proton and are in sharp contrast to the result without water. Of course, the coarse-grained potential includes the average between different orientations for the water molecules as well the methane molecule, but the curves in Figure 1 show that the interactions that are behind the $\mathrm{LJ}$ parameters are those that appear between the zeolite-proton-water complexes and hydrocarbon molecules.

Using the obtained potential parameters, we show in Figure $2 \mathrm{~b}$ and Figure $2 \mathrm{c}$ the predictions of our coarse-graining approach and available experimental data. The agreement with experimental data not included in the calibration set is remarkable, not only for the structure with $2 \mathrm{H}^{+}$per unit cell of the calibration data but also with 3 and $4 \mathrm{H}^{+}$per unit cell. This agreement is transferable to other protonated aluminosilicate frameworks as shown in Figure 2d.

We have demonstrated the usefulness of coarse-graining for adsorption studies. Our approach gives predictions on adsorption properties with very high accuracy. It is an interesting question why this is indeed the case. In principle, one might fit an oversimplified model and inaccuracies can be made to cancel out. However, such an imbalance will manifest itself in poor model performance beyond the calibration set. ${ }^{17} \mathrm{~A}$ crucial aspect might lie in the fitting procedure. When parameters are obtained from experimental isotherms, one actually fits directly to data under experimental conditions. We fit not only to energetics but also to entropy effects. Experimental free-energy data contain information on energetic and thermodynamic and statical properties of the system. Current QM methods are unable to provide the latter. Isotherms afford excellent parameterization because all the structural, thermodynamic, and statistical data are available at different loadings and temperatures. The coarsegraining approach based on effective potential provides a direct link with experimental conditions and also a physical and very efficient simulation framework for adsorption of nonpolar molecules in protonated aluminosilicates.

Acknowledgment. We would like to thank the Spanish "Ministerio de Educación y Ciencia" (Ramón y Cajal Program and project CTQ2004-00582/BQU, CTQ2004-07730-C02-01/ BQU, VEM2003 20574 C03 01), The Netherlands Research Council for Chemical Sciences (NWO-CW), and Chevron Texaco for financial support.

\section{References and Notes}

(1) Davis, M. E. Science 2003, 300, 438-439.

(2) Lai, Z.; Bonilla, G.; Diaz, I.; Nery, J. G.; Sujaoti, K.; Amat, M. A.; Kokkoli, E.; Terasaki, O.; Thompson, R. W.; Tsapatsis, M.; Vlachos, D. G. Science 2003, 300, 456-460.

(3) Dubbeldam, D.; Calero, S.; Vlugt, T. J. H.; Krishna, R.; Maesen, T. L. M.; Smit, B. J. Phys. Chem. B 2004, 108, 12301-12313.

(4) Malka-Edery, A.; Abdallah, K.; Grenier, P.; Meunier, F. Adsorption 2001, 7, 17-25.

(5) Olson, D. H.; Haag, W. O.; Borghard, W. S. Microporous Mesoporous Mater. 2000, 35-36, 435-446. 
(6) Jentys, A.; Warecka, G.; Derewinski, M.; Lercher, J. A. J. Phys. Chem. 1989, 93, 4837-4843.

(7) Ryckaert, J. P.; Bellemans, A. Faraday Discuss. Chem. Soc. 1978, 66, 95-106.

(8) Bezus, A. G.; Kiselev, A. V.; Lopatkin, A. A.; Du, P. Q. J. J. Chem. Soc., Faraday Trans. 2 1978, 74, 367-379.

(9) Martin, M. G.; Thompson, A. P.; Nenoff, T. M. J. Chem. Phys. 2001, 114, 7174-7181.

(10) Dubbeldam, D.; Calero, S.; Vlugt, T. J. H.; Krishna, R.; Maesen,

T. L. M.; Beerdsen, E.; Smit, B. Phys. Rev. Lett. 2004, 93, 088302-1.

(11) Calero, S.; Dubbeldam, D.; Krishna, R.; Smit, B.; Vlugt, T. J. H.; Denayer, J. F. M.; Martens, J. A.; Maesen, T. L. M. J. Am. Chem. Soc. 2004, 126, 11377-11386.

(12) van Koningsveld, H.; van Bekkum, H.; Jansen, J. C. Acta Crystallogr. 1987, B43, 127-132.

(13) Drago, R. S.; Webster, C. E.; McGilvray, J. M. J. Am. Chem. Soc. 1998, $120,538-547$

(14) Mejías, J. A.; Lago, S. J. Chem. Phys. 2000, 113, 7306-7316.

(15) Mejías, J. A.; Hamad, S.; Lago, S. J. Phys. Chem. B 2001, 105, 9872-9878.

(16) Frisch, M. J.; Trucks, G. W.; Schlegel, H. B.; Scuseria, G. E.; Robb, M. A.; Cheeseman, J. R.; Montgomery, J. A., Jr.; Vreven, T.; Kudin, K. N.; Burant, J. C.; Millam, J. M.; Iyengar, S. S.; Tomasi, J.; Barone, V.; Mennucci, B.; Cossi, M.; Scalmani, G.; Rega, N.; Petersson, G. A.; Nakatsuji, H.; Hada, M.; Ehara, M.; Toyota, K.; Fukuda, R.; Hasegawa, J.; Ishida, M.; Nakajima, T.; Honda, Y.; Kitao, O.; Nakai, H.; Klene, M.; Li, X.; Knox, J. E.; Hratchian, H. P.; Cross, J. B.; Bakken, V.; Adamo, C.; Jaramillo, J.; Gomperts, R.; Stratmann, R. E.; Yazyev, O.; Austin, A. J.; Cammi, R.; Pomelli, C.; Ochterski, J. W.; Ayala, P. Y.; Morokuma, K.; Voth, G. A.; Salvador, P.; Dannenberg, J. J.; Zakrzewski, V. G.; Dapprich, S.; Daniels, A. D.; Strain, M. C.; Farkas, O.; Malick, D. K.; Rabuck, A. D.; Raghavachari, K.; Foresman, J. B.; Ortiz, J. V.; Cui, Q.; Baboul, A.
G.; Clifford, S.; Cioslowski, J.; Stefanov, B. B.; Liu, G.; Liashenko, A.; Piskorz, P.; Komaromi, I.; Martin, R. L.; Fox, D. J.; Keith, T.; Al-Laham, M. A.; Peng, C. Y.; Nanayakkara, A.; Challacombe, M.; Gill, P. M. W.; Johnson, B.; Chen, W.; Wong, M. W.; Gonzalez, C.; Pople, J. A. Gaussian 03; Gaussian, Inc.: Wallingford, CT, 2004.

(17) Donchev, A. G.; Ozrin, V. D.; Subbotin, M. V.; Tarasov, O. V.; Tarasov, V. I. Proc. Natl. Acad. Sci. U.S.A. 2005, 102, 7829-7834.

(18) Czjzek, M.; Jobic, H.; Fitch, A. N.; Vogt, T. J. Phys. Chem. 1992, $96,6,1535-1540$.

(19) Jirak, Z.; Vratislav, S.; Bosacek, V. J. Phys. Chem. Solids 1980 41,1089 .

(20) Sun, T.; Seff, K. J. Phys. Chem. 1993, 97, 7719-7723.

(21) Olson, D. H.; Dempsey, E. J. Catal. 1969, 13, 221.

(22) Sauer, J. J. Mol. Catal. 1989, 54, 312.

(23) Choi, S. G.; Lee, S. H. Bull. Korean Chem. Soc. 1999, 20, 445450 .

(24) Eder, F.; Stockenhuber, M.; Lercher, J. A. J. Phys. Chem B. 1997, $101,5413-5419$.

(25) Narbeshuber, T. F.; Vinek, H.; Lercher, J. A. J. Catal. 1995, 157 , $388-395$.

(26) de Gauw, F. J. M. M.; van Grondelle, J.; van Santen, R. A. J. Catal. 2002, 206, 295-304.

(27) Doelle, H. J.; Heering, J.; Riekert, L.; Marosi, L. J. Catal. 1981, $71,27-40$.

(28) Kotrel, S.; Rosynek, M. P.; Lunsford, J. H. J. Phys. Chem. B 1999, $103,818-824$.

(29) Noordhoek, N. J.; Schuring, D.; de Gauw, F. J. M. M.; Anderson, B. G.; de Jong, A. M.; de Voigt, M. J. A.; van Santen, R. A. Ind. Eng. Chem. Res. 2002, 41, 1973-1985.

(30) Arik, I. C.; Denayer, J. F.; Baron, G. V. Microporous Mesoporous Mater. 2003, 60, 111-124 